\title{
Calixarenos. II. Aplicações
}

\author{
Sandra Félix, *,a,c Paula M. Marcos ${ }^{B, C}$
}

Os calixarenos possuem uma extrema versatilidade para complexar e transportar iões e moléculas neutras de um modo selectivo. Considerando a relativa facilidade com que os compostos de partida podem ser sintetizados e posteriormente modificados, juntamente com a grande variedade de tamanhos da cavidade do macrociclo, estes compostos tornam-se muito atractivos para aplicações industriais. A análise de resultados obtidos à escala laboratorial tem conduzido a inúmeras aplicações dos calixarenos, as quais se têm traduzido quer no elevado número de patentes registadas, quer mesmo através de aplicações industriais já concretizadas. O presente artigo faz uma revisão geral deste tema, com especial enfoque nos principais campos de aplicação dos calixarenos, nomeadamente: catálise, separações iónicas e moleculares e sensores de vários tipos. Referem-se também as últimas patentes envolvendo a aplicação deste tipo de compostos.

\section{INTRODUÇÃO}

Uma das características mais importantes dos calixarenos é a sua extrema versatilidade para complexar e transportar iões e moléculas neutras de um modo selectivo. Como foi descrito no artigo publicado anteriormente [1], os compostos de partida podem ser sintetizados e posteriormente modificados (nas coroas superior e inferior) através de sínteses relativamente fáceis, e por outro lado podem obter-se macrociclos com cavidades de tamanhos consideravelmente diferentes, o que torna esta classe de compostos muito atractivos para aplicações industriais. Existem mais de 400 patentes registadas descrevendo aplicações de moléculas baseadas nestes compostos macrocíclicos. Muitas destas patentes dizem respeito às propriedades ionofóricas de calixarenos capazes de coordenar iões metálicos, predominantemente catiões alcalinos e alcalino-terrosos.

Devido à importância vital que os catiões $\mathrm{Na}^{+}, \mathrm{K}^{+}, \mathrm{Mg}^{2+}$ e $\mathrm{Ca}^{2+}$ têm no organismo humano, surgiram, a partir do fim da década de 1960, vários receptores sintéticos macrocíclicos. Estes eram constituídos essencialmente por cavidades centrais circulares e hidrófilas, contendo átomos ligantes electronegativos e esqueletos exteriores fle-

\footnotetext{
A Universidade Atlântica, Antiga Fábrica da Pólvora de Barcarena, 2730-036 Barcarena

Faculdade de Farmácia da Universidade de Lisboa, Av. Prof. Gama Pinto, 1649-003 Lisboa Centro de Ciências Moleculares e Materiais, FCUL,
Edifício C8, 1749-016 Lisboa
}

xíveis e hidrófobos. Ao contrário dos éteres de coroa (primeiros ligandos macrocíclicos neutros eficientes para aqueles tipos de catiões) e dos esferandos, que possuem apenas uma cavidade circular a duas dimensões, os calixarenos, assim como os criptandos, contêm cavidades tridimensionais capazes de rodear completamente o catião e protegê-lo assim do meio exterior. Relativamente àqueles últimos macrociclos, a cavidade dos calixarenos não é tão rígida, tornando-se assim mais versátil.
$5,6,8 ; \mathrm{R}=\mathrm{H}, t-\mathrm{Bu} ; \mathrm{Y}=\mathrm{R}^{\prime}, \mathrm{OR}^{\prime}, \mathrm{NR}_{2}$, $\mathrm{OH})$. Mais recentemente, têm vindo a ser sintetizados calixarenos contendo átomos dadores mais macios do que o oxigénio, tais como o azoto (outros grupos funcionais), o enxofre e o fósforo. Os estudos de complexação têm também sido estendidos a outros catiões metálicos, como os de transição, pesados e lantanídeos, devido à importância (ambiental, económica, na saúde, entre outras) que estes catiões têm na sociedade actual. Para além dos calixarenos funcionalizados,

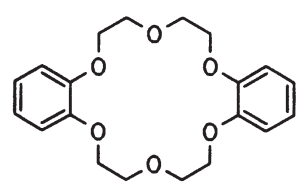

I

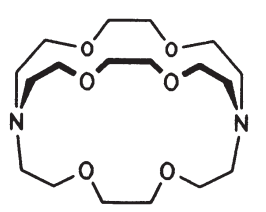

II

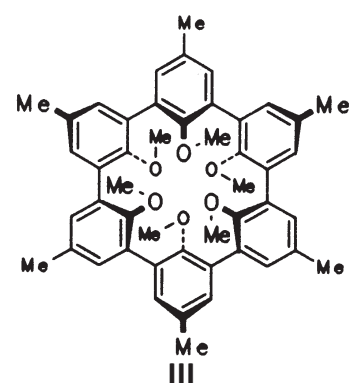

III

Figura 1 Exemplos de um éter de coroa (I), um criptando (II) e um esferando (III)

Muito embora os éteres lineares só muito dificilmente formem complexos, sabe-se que nos casos em que isso acontece a quelação é mais eficiente quando os átomos de oxigénio ligantes estão separados por dois átomos de carbono; sabendo-se também que nos éteres de coroa a ligação mais favorável à complexação é $-\mathrm{OCH}_{2} \mathrm{CH}_{2} \mathrm{O}$-, os derivados calixarénicos estudados apresentam, frequentemente, a estrutura $1(n=4$, também os calixarenos precursores (2) podem formar complexos, sobretudo com moléculas neutras, conduzindo a aplicações com interesse. Além disso, as propriedades físico-químicas dos calixarenos, nomeadamente elevados pontos de fusão, alta estabilidade térmica e química, baixa solubilidade em muitos solventes orgânicos e baixa toxicidade, são bastante importantes para o seu potencial uso em determinadas aplicações. 


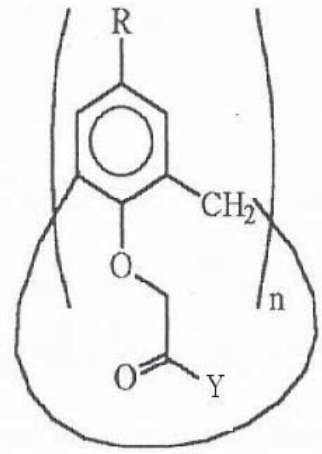

1 a $n=6, R=t-B u, Y=O H$

b $\mathrm{n}=6, \mathrm{R}=$ hexilo, $\mathrm{Y}=\mathrm{OH}$

c $\mathrm{n}=6, \mathrm{R}=t-\mathrm{Bu}, \mathrm{Y}=\mathrm{NHOH}$

d $\mathrm{n}=8, \mathrm{R}=t-\mathrm{Bu}, \mathrm{Y}=\mathrm{NEt}_{2}$

e $n=4, R=t-B u, Y=O E t$

f $\mathrm{n}=4, \mathrm{R}=t-\mathrm{Bu}, \mathrm{Y}=\mathrm{SEt}_{2}$

\section{Aplicações dos calixarenos}

A análise de resultados obtidos à escala laboratorial tem conduzido a inúmeras aplicações dos calixarenos, as quais se têm traduzido quer no elevado número de patentes registadas, quer mesmo através de aplicações industriais já concretizadas.

\section{Catálise}

A grande versatilidade dos calixarenos como agentes de complexação levou à aplicação de alguns derivados como catalisadores em reacções de síntese e, em particular, na mimetização de enzimas. Estes compostos podem actuar como agentes de transferência de fase ou como agentes receptores. Em sistemas reaccionais envolvendo um sal inorgânico (em fase aquosa) cujo anião participa activamente na transformação a levar a cabo em meio orgânico, a utilização de um agente de transferência de fase ao qual o ião metálico se coordene formando um complexo de carga positiva, possibilita que o anião seja transportado para a fase orgânica como contra-ião, participando assim na reacção. Vários calixarenos têm sido utilizados para este fim, sobretudo derivados de calix[6]arenos, mas também calix[4]arenos contendo cadeias polietilénicas e grupos amida como substituintes.

Os derivados 3a-c foram também usados com sucesso como agentes de transferência de fase reversa; neste

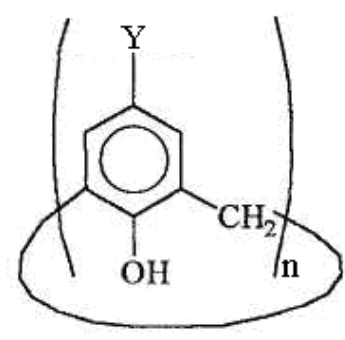

2

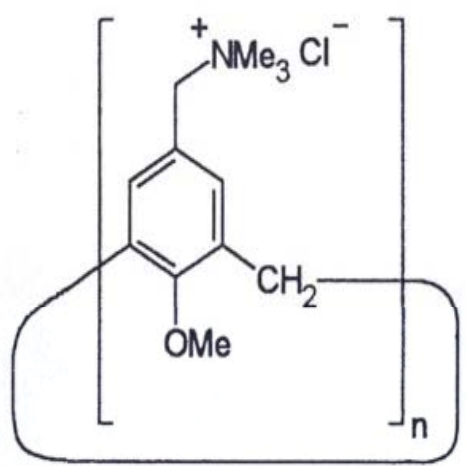

3 a $\mathrm{n}=4$

b $\mathrm{n}=6$

c $\mathrm{n}=8$ caso, a reacção dá-se em meio aquoso e são usados calixarenos hidrossolúveis para transportar para esta fase uma espécie catalítica orgânica.

Por outro lado, um calixareno poderá com facilidade possuir grupos fortemente hidrofílicos, que lhe permitam ser solúvel em água, e uma cavidade hidrofóbica capaz de complexar com determinado substracto. Os calixarenos 4 (na forma de sal de sódio), 5 e 6 apresentam este comportamento, o que tem levado à sua aplicação como receptores catalíticos em sistemas homogéneos. No que respeita à construção de modelos enzimáticos, têm sido usados sobretudo derivados de calix[6]arenos, devido ao tamanho da respectiva cavidade.
Estes sistemas têm permitido efectuar o estudo mecanístico da função de metaloenzimas de zinco e cobre. Anteriormente, tinha também sido utilizado o sal de bário do $p$-terc-butilcalix[4]coroa-5 (7) como catalisador da clivagem de ésteres de arilo, e o estudo mecanístico do sistema mostrou que este composto, que efectivamente actua como uma esterease artificial, se comporta de modo semelhante ao de certos enzimas proteolíticos, como é o caso da a-quimotripsina. Recentemente, têm sido sintetizados péptido- (8a) e glicocalixarenos (8b) e ainda derivados mistos apresentando estas duas funcionalidades, sendo uma das suas potenciais aplicações a mimetização de glicoproteínas.

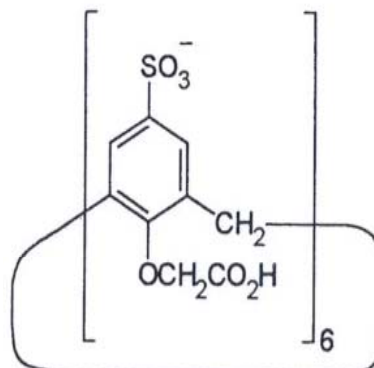

4

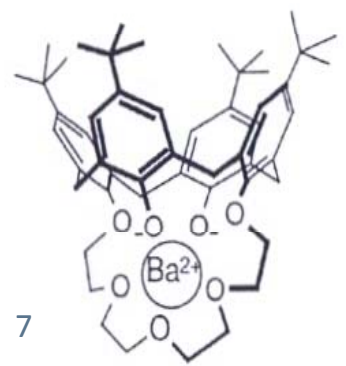

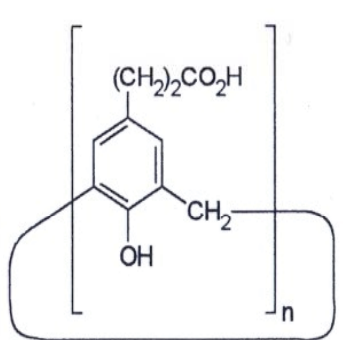

5

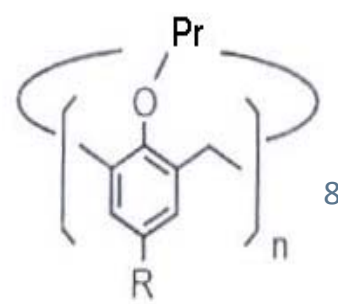

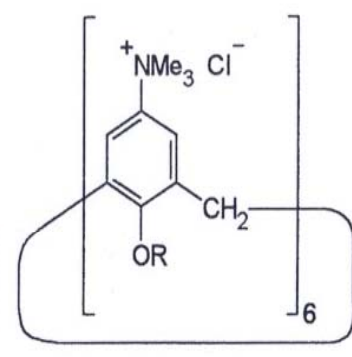

6
8 a $n=4, R=$ açúcar b $\mathrm{n}=4, \mathrm{R}=$ péptido c $\mathrm{n}=6, \mathrm{R}=t-\mathrm{Bu}$ 


\section{SEPARAÇõES IÓNICAS}

A utilização de calixarenos neste tipo de aplicação tem-se concretizado essencialmente no tratamento de resíduos radioactivos. Nos últimos anos, tem-se procurado encontrar formas de remover os radionuclidos de vida longa dos resíduos nucleares, para que estes possam armazenar-se com menos consequências e maior segurança. Após a remoção dos radionuclidos de césio, de estrôncio, dos actinídeos e dos lantanídeos, estes são separados e os lantanídeos purificados para reutilização em diversas aplicações, como a obtenção de materiais catalíticos ou sondas luminescentes, ou ainda como agentes de contraste em imagiologia, entre outras.

No tratamento de resíduos radioactivos, os calixarenos têm sido usados, sobretudo, na remoção de iões césio e de urânio de resíduos aquosos, por transporte do catião para uma fase receptora por meio de membranas de suporte líquido, ou simplesmente pela sua extracção para uma fase orgânica.

A recuperação de catiões $\mathrm{Cs}^{+}$foi o assunto da primeira patente envolvendo a aplicação de calixarenos, depositada em 1984. Este trabalho envolve a aplicação de calixarenos precursores, nomeadamente os p-terc-butilcalix[4]-, [6]- e [8]arenos (2) na remoção de catiões alcalinos de meio aquoso básico. Nestas condições, ocorre a desprotonação dos grupos hidroxilo, fazendo-se o transporte dos catiões para uma fase receptora através da formação de complexos neutros. Todos os calixarenos, com especial evidência para o octâmero, mostraram preferência para o césio, que transportam selectivamente em presença de outros catiões. Dentro das calixcoroas, que apareceram mais tarde, as calix[4]coroas- 6 em particular constituem uma família de compostos com grande afinidade para o $\mathrm{Cs}^{+}$. As calixcoroas simples 1,3-disubstituídas (9) e as calixbiscoroas (10), na conformação 1,3-alternada, são excelentes agentes extractantes e transportadores deste catião, chegando alguns derivados a apresentar selectividades de extracção $\mathrm{Cs}^{+} / \mathrm{Na}^{+}$da ordem das dezenas de milhar, o mesmo aconte- cendo no transporte. Estes compostos apresentam-se assim como potenciais candidatos à remoção de césio de resíduos radioactivos à escala industrial. Foi já desenvolvido para o efeito um processo testado com sucesso em amostras de resíduos desta natureza.

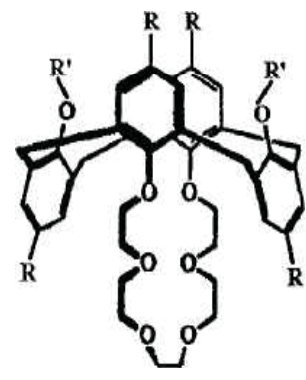

$\mathrm{R}, \mathrm{R}^{\prime}=$ alquilo

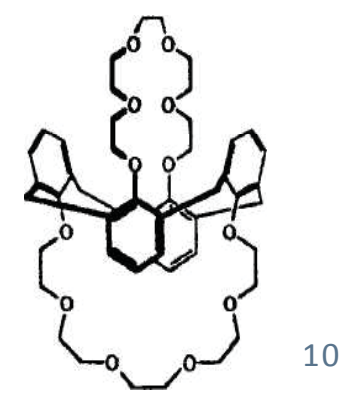

Embora em muito menor número do que no caso anterior, existem também alguns exemplos de calixarenos capazes de remover urânio de meios aquosos.

A ideia baseou-se na geometria do ião $\mathrm{UO}_{2}{ }^{2+}$, cuja esfera de coordenação é ideal para a complexação com certos calix[6]arenos.

A síntese e aplicação de uranófilos altamente selectivos é importante, não só para o tratamento de resíduos radioactivos, mas também para a extracção do ião uranilo da água do mar, devido à importância do urânio nas questões energéticas.

As patentes depositadas são sobretudo japonesas e constam da extracção de $\mathrm{UO}_{2}{ }^{2+}$ de meios fortemente ácidos ou básicos para uma fase orgânica contendo um calixareno-derivado hexamérico.

O melhor resultado alcançado envolveu a aplicação dos hexaácidos carboxílicos do p-terc-butil- e do $p$-hexilcalix[6]areno (1a e $\mathbf{1 b}$, respectivamente) - o primeiro chamado "superuranófilo" -, que extraem o ião uranilo quase quantitativamente em meio básico. Existem outros uranófilos eficazes, hexaméricos, como o ácido hidroxâmico 1c, mas não só, como é o caso do sal de sódio do p-sulfonatocalix[5]areno (11a).

No que respeita à extracção de estrôncio, existem também alguns estudos envolvendo amidas de calix[4]-, calix[6]- e calix[8]arenos, com as quais se obtêm bons resultados.

Em particular, o octâmero 1d mostrou ser um extractante bastante eficiente para esta espécie, apresentado selectividades $\mathrm{Sr}^{2+} / \mathrm{Na}^{+}$superiores a 20000.

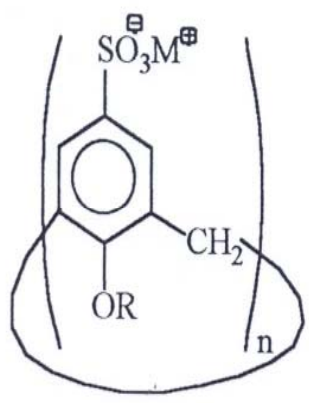

$$
\begin{array}{r}
11 \text { a } n=5, M=N a, R=H \\
\text { b } n=6, M=N a, R=H
\end{array}
$$

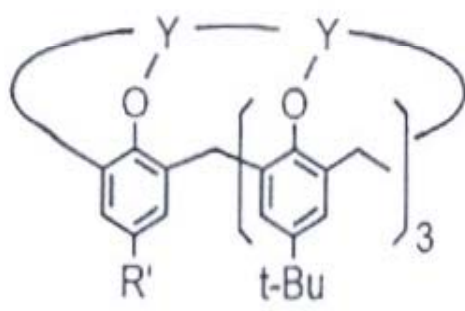

$$
\begin{aligned}
& \mathrm{Y}=\mathrm{CH}_{2} \mathrm{COOR}(\mathrm{R}=\text { alquilo }), \\
& \mathrm{R}^{\prime}=\text { ligação a sílica }
\end{aligned}
$$

\section{Separações moleculares}

Devido às suas capacidades de inclusão, os calixarenos podem ser usados como aditivos em cromatografia e em electroforese, para controlar a selectividade e eficiência das separações.

O sal de sódio do $p$-sulfonatocalix[6]areno (11b) foi usado como aditivo da solução-tampão na separação de isómeros de clorofenóis, benzenodióis e toluidinas por electroforese capilar. Conseguiu-se assim ( $\mathrm{pH}=7-8$ ) a completa separação dos três isómeros de cada uma das classes de compostos 
estudada, o que não acontecia nas mesmas condições sem a presença do aditivo. A adição deste calixareno iónico conduziu também ao aumento da eficácia de separação de uma mistura de vitaminas lipossolúveis, pela mesma técnica, em meio ácido.

Com vista a um estudo sobre as propriedades de inclusão de moléculas de solventes orgânicos por parte do $p$-terc-butilcalix[4]areno, este foi usado como fase estacionária de uma coluna de microenchimento, determinando-se então, por cromatogafia gasosa, os tempos de retenção de diversos solventes.

Os resultados deste estudo poderão ser bastante importantes em futuras aplicações como fase estacionária em cromatografia. O mesmo composto, ligado a uma matriz de sílica-gel, deu origem a um material de enchimento usado com sucesso na separação de biomoléculas, nomeadamente as $o$-, $m$ - e $p$-nitroanilinas. Materiais de enchimento semelhantes foram obtidos a partir dos derivados 12 , que foram usados para a separação de benzenos dissubstituídos, hidrocarbonetos aromáticos policíclicos (PAHs), bases purínicas e pirimidínicas e nucleósidos por cromatografia líquida.

Está patenteada uma fase estacionária deste tipo baseada no hexaéter propílico do p-terc-butilcalix[6]areno 8c, eficiente na separação de PAHs e fulerenos por cromatografia líquida. Existem ainda outros exemplos do uso de calixarenos como fase estacionária para a separação de diversos compostos, por diferentes técnicas.

\section{Sensores}

A construção de sensores utilizando calixarenos tem a ver directamente com as propriedades ionofóricas destes compostos.

São bastantes os exemplos de derivados aplicados com sucesso na construção de eléctrodos, como Eléctrodos Selectivos a Iões (ISEs), Transdutores com Efeito de Campo Selectivos a Iões (ISFETs) ou Transdutores com Efeito de Campo Modificados Quimicamente (CHEMFETs). Outros

tipos de sensores têm sido obtidos com base nestes compostos, nomeadamente sensores ópticos (essencialmente fluorescentes e cromogénicos) e compostos com propriedades ópticas não lineares.

Os ISEs são sistemas simples, de um modo geral constituídos por um eléctrodo de $\mathrm{Ag} / \mathrm{AgCl}$ mergulhado num electrólito (referência interna) e uma membrana selectiva onde está incorporado o calixareno.

Quanto aos ISFETs, são sensores potenciométricos cuja produção envolve a combinação de membranas selectivas (ISEs) com semicondutores (circuitos integrados), onde é utilizado um transístor de efeito de campo para medir a diferença de potencial na membrana. Os CHEMFETs são, como o nome indica, ISFETs modificados, geralmente por inserção de um hidrogel hidrofílico entre a membrana e a superfície isoladora.

As calixcoroas e os derivados éster e cetona têm sido os compostos mais usados para a construção de eléctrodos selectivos para metais alcalinos. 0 dietóxido do p-terc-butilcalix[4]arenocoroa-5, na conformação cone parcial 13, mostrou-se bastante eficaz para o catião $\mathrm{K}^{+}$, tanto em ISEs como em ISFETs. Vários tipos de eléctrodos selectivos usando o tetraéster etílico do p-terc-butilcalix[4]areno (1e) têm sido testados com êxito na determinação da concentração de $\mathrm{Na}^{+}$no sangue.

Para outros metais, como é o caso da prata e do chumbo, começaram já a aplicar-se derivados contendo heteroátomos. É o caso da tetra(dietil)tioamida do $p$-terc-butilcalix[4]areno (1f), usada para construir um eléctrodo de PVC selectivo para $\mathrm{Pb}^{2+}$.

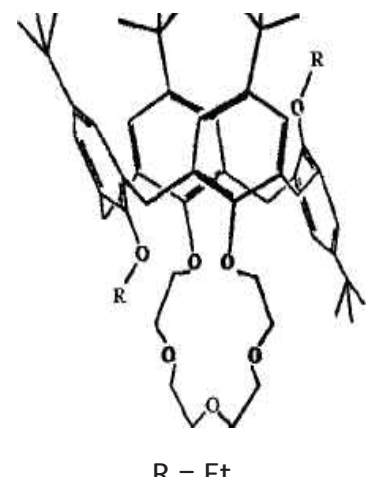

13
O derivado 14 , testado como agente para a detecção de $\mathrm{Pb}^{2+}$, mostrou uma resposta excelente e uma selectividade relativamente aos iões $\mathrm{Ag}^{+}, \mathrm{Cu}^{2+}$ e $\mathrm{Cd}^{2+}$ superior a ligandos disponíveis comercialmente para a detecção daquele ião. Vários ISEs e CHEMFETs para $\mathrm{Ag}^{+}, \mathrm{Cu}^{2+}, \mathrm{Cd}^{2+}$, $\mathrm{Pb}^{2+}$ e ião guanidínio foram já construídos recorrendo ao uso de outros derivados contendo heteroátomos.

Têm também sido usados filmes de calixarenos precursores em microssensores baseados em estruturas de ISFETs e EISs (sensores de Semicondutor-Isolador-Electrólito), para a detecção de vários metais. Os EISs são microssensores que utilizam como membrana, em geral, um filme fino de silício.

Nos casos referidos, as membranas usadas são constituídas por um filme de calixareno depositado sobre o filme de silício, o que é feito por evaporação térmica sob vácuo; este tratamento confere um maior tempo de vida ao sensor, comparando com as membranas tradicionais. Assim, os sistemas testados têm um elevado potencial de aplicação industrial.

Cromoionóforos sintéticos sensíveis a catiões alcalinos são de grande importância na eventual aplicação que podem ter em análises clínicas.

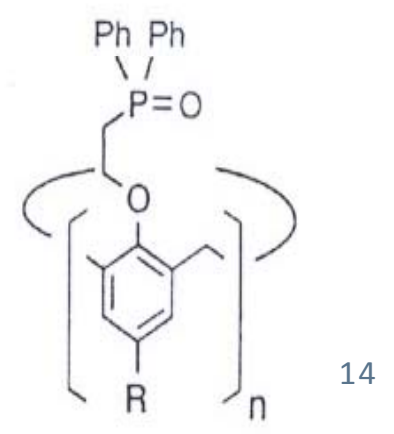

O grupo indoanilina apresenta diferenças consideráveis nas suas propriedades ópticas quando sujeito a estímulos químicos, pelo que moléculas contendo este sistema são fortes candidatas a esse tipo de aplicação. Isto quer dizer que, se compostos com este tipo de propriedades possuírem também uma forte afinidade de complexação com determinadas espécies, então são potenciais sen- 
sores ópticos. É o caso dos compostos $15 a$ e 16, que reúnem condições para serem aplicados como sensores ópticos na detecção de $\mathrm{Na}^{+}$. O composto $15 \mathrm{~b}$ foi aplicado com sucesso como sensor óptico para o $\mathrm{Ca}^{2+}$.

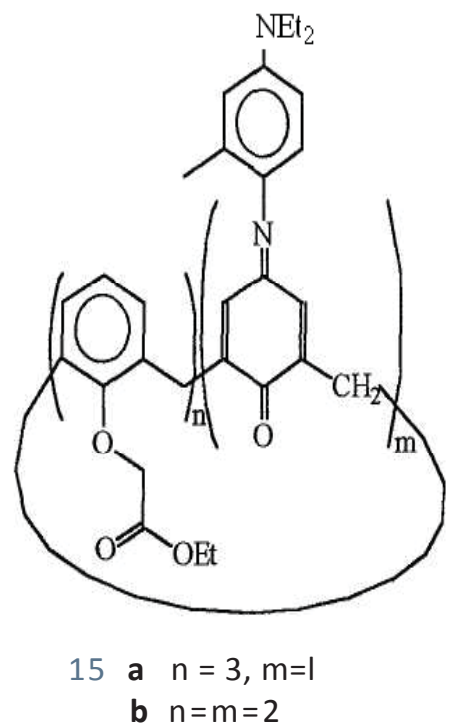

Outro tipo de sensores ópticos funciona com base na fluorescência. Podem ser obtidos sensores fluorescentes usando derivados calixarénicos com substituintes policíclicos aromáticos (por exemplo, o antraceno ou o pireno) na coroa inferior. São sensores bastante sensíveis e por isso assumem especial importância em situações em que se consegue um nível igualmente bom de selectividade para espécies contaminantes, como o $\mathrm{Pb}^{2+}$, por exemplo.

Sensores ópticos baseados em calixarenos têm sido aplicados, não só a iões, como também a moléculas, e inclusivamente tem sido estudada a possibilidade de construção de sensores cromogénicos e fluorescentes baseados em calixarenos quirais, capazes de distinguir enantiómeros entre si. Esta possibilidade seria de grande interesse para aplicação, por exemplo, na indústria farmacêutica, onde uma das principais dificuldades se prende exactamente com a separação dos princípios activos dos respectivos enantiómeros.

A utilização de compostos baseados em calixarenos com propriedades ópticas não lineares tem sido essencialmente direccionada para o desenvol- vimento de materiais que funcionem como guias de ondas, que possam vir a ser aplicados em lasers, dispositivos electrónicos ou em comunicações.

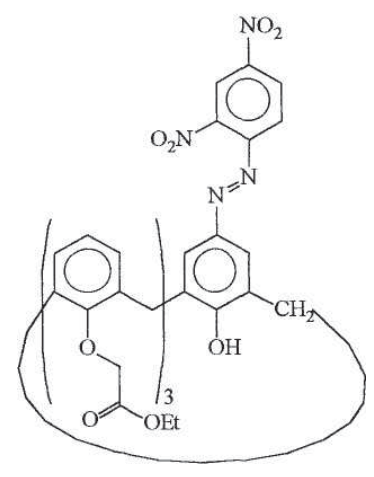

16

Mais recentemente, foi desenvolvida uma nova classe de ionóforos, os chamados calixtubos, que são derivados bis-calixarénicos cuja selectividade vai depender, não só dos substituintes e do diâmetro da cavidade, mas também do comprimento desta. Em particular, os resultados de ensaios laboratoriais efectuados com calix[4]tubos mostram o grande potencial do composto 17 como sensor para o potássio e de calix[4]semitubos modificados (18) como sensores redox para o rubídio e para o césio.

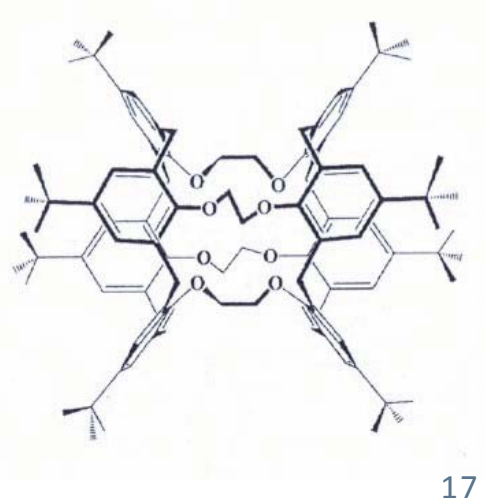

\section{OUtRAS APLICAÇõES}

Como se pode confirmar pela leitura deste artigo, os calixarenos são compostos com eficácia comprovada em variadas aplicações. Presentemente, muitas são as áreas de aplicação dos calixarenos e seus derivados, com vista a uma possível implementação de processos a nível industrial.

Um dos temas mais actuais no que respeita à investigação científica são as aplicações a sistemas biológicos, com tudo o que esta designação pode abranger, e a área da síntese e aplicação de calixarenos não é excepção. Para além da mimetização de enzimas e outras moléculas biológicas, como já foi referido anteriormente, esta classe de compostos tem sido vastamente estudada no reconhecimento de espécies com importância biológica. $\mathrm{Pa}$ ralelamente às espécies iónicas, que continuam a ser estudadas, têm-se obtido nos últimos tempos derivados de calixarenos com propriedades de reconhecimento para moléculas biológicas, essencialmente hidratos de carbono, proteínas e respectivos "monómeros". Têm sido também obtidos calixarenos com actividade farmacológica, nomeadamente como agentes anticoagulantes e antibióticos, aparentemente devido às suas capacidades de reconhecimento molecular.

Outra área emergente é a aplicação de nanomateriais baseados em calixarenos como sensores e fixadores de gases. Por exemplo, foram usados com sucesso materiais baseados em calix[4]arenos tetra-alquilados para o encapsulamento de $\mathrm{NO}_{x}$, o que constitui um resultado que pode vir a ter repercussões importantes a nível

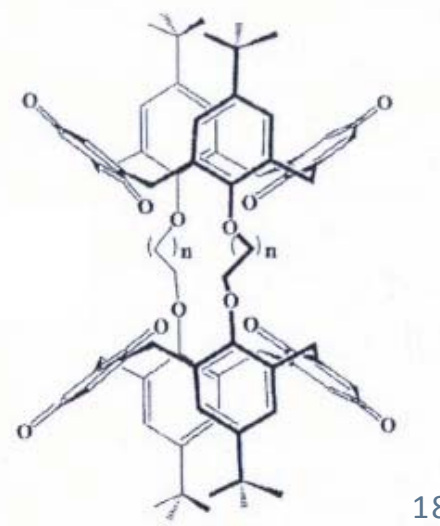

ambiental e clínico. Um material polimérico, cujas unidades são derivados calixarénicos contendo grupos ureia e aminoácido, mostrou resultados satisfatórios como potencial sensor óptico para o $\mathrm{CO}_{2}$.

\section{Patentes}

Além dos exemplos atrás referidos, existem publicações referindo a aplicação de calixarenos à escala industrial, ou essa possibilidade. Em particular, há registo de largas centenas de 
patentes com referência a calixarenos, e muitas delas envolvendo a aplicação directa de compostos deste tipo. Como já foi referido, a primeira patente registada envolvendo calixarenos data de 1984 e refere-se à aplicação de calixarenos precursores na extracção de $\mathrm{Cs}^{+}$. Deve contudo salientar-se que, embora esta patente seja a primeira que diz respeito a este tipo de compostos já com o nome calixarenos e apresentados tal como os conhecemos hoje, existem trabalhos anteriores envolvendo compostos que hoje verificamos tratar-se de calixarenos, mas que não tinham ainda essa designação, até porque a sua estrutura não estava ainda estabelecida.

Entretanto, muitas outras patentes foram registadas no âmbito do tratamento de resíduos radioactivos, não só respeitantes à extracção de $\mathrm{Cs}^{+}$, mas também de outros iões metálicos. Trata-se de um assunto que continua a suscitar interesse e a conduzir ao registo de patentes. Por exemplo, foi recentemente patenteada a utilização de uma calixbiscoroa na extracção conjunta de $\mathrm{Cs}^{+}$e $\mathrm{Sr}^{+}$de meios acídicos [2]. Uma outra aplicação de calixarenos já bastante explorada industrialmente é o uso de determinados derivados como aceleradores de secagem em adesivos instantâneos (cianoacrilatos). Existem bastantes patentes descrevendo estes processos, alguns dos quais já aplicados a produtos disponíveis no mercado.

Aparentemente, o modo de acção dos calixarenos usados nestas aplicações consiste em possibilitarem a "libertação" dos iniciadores de polimerização aniónicos, por complexação com os respectivos contra-catiões. Os aditivos calixarénicos são introduzidos na composição das colas em cerca de 0,1 a $1 \%$ (em massa), quantidade suficiente para que os tempos de secagem passem de alguns minutos para alguns segundos. Vários tipos de derivados têm sido aplicados com sucesso neste campo, sobretudo calixarenos e oxacalixarenos contendo o grupo carbonilo, nomeadamente derivados éster e cetona e derivados com funcionalidades mistas. Também no campo da aplicação de derivados calixarénicos a diversos tipos de sensores, muitas patentes têm sido e continuam a ser registadas. $A$ maioria refere-se a dispositivos utiliza- dos na detecção de catiões metálicos, sobretudo aqueles que têm interesse clínico, mas existem também registos referentes a sensores moleculares. Por exemplo, foi recentemente depositada uma patente envolvendo a aplicação de derivados calixarénicos simples, como tetrâmeros tetra-alquilados, na detecção de gases $\mathrm{NO}_{x}$ na atmosfera [3]. Outra aplicação interessante patenteada é a utilização de sais de sulfonato-calixarenos e acetato-calixarenos na detecção de colesterol contido em lipoproteínas de muito baixa densidade (VLDL) no soro humano [4].

No que respeita a aplicações biológicas, uma área em que apareceram já as primeiras patentes descrevendo a aplicação de calixarenos é a farmacologia. Nomeadamente, no campo da anestesiologia, foram usados $p$-sulfonilcalix[6]- e [8]arenos como agentes quelantes para drogas de indução de bloqueio neuromuscular [5]. Foi também patenteado o uso de vários calixarenos como excipientes de princípios activos de fármacos [6]. Foi muito recentemente patenteada outra aplicação importante de calixarenos na área da saúde, e que envolve a utilização de diversos derivados no revestimento de implantes cirúrgicos [7].

Existem ainda muitas patentes, registadas sobretudo nos anos 80 e 90 do século $X X$, que descrevem a utilização de calixarenos em aplicações tão diversas como iniciadores e estabilizadores de polímeros orgânicos, fases estacionárias em métodos de separação, síntese orgânica, agentes de contraste em meios auxiliares de diagnóstico clínico, aditivos de lubrificantes, corantes, entre outras. Actualmente, continuam a aparecer registos de patentes envolvendo o uso de calixarenos em algumas destas aplicações. Como se mostra neste artigo, esta classe de compostos orgânicos continua a ser de grande interesse, não só no que diz respeito à síntese de novos derivados, mas sobretudo na previsão de estruturas com certas características, com vista à sua aplicação em determinados campos.

\section{Nota}

O termo "complexo" foi aqui utilizado em sentido amplo, incluindo as associações moleculares.

\section{Abreviaturas}

CHEMFET - Chemical Modified Field Effect Transistors

EIS - Electrolyte-Insulator-Semiconductor ISE - Ion Selective Electrodes

ISFET - Ion Selective Field Effect Transistors

PAH - Policyclic Aromatic Hydrocarbons

SLM - Supported Liquid Membranes

VLDL - Very Low Density Lipoproteins

\section{REFERÊNCIAS}

[1] P. M. Marcos, S. Félix, Química 107 (2007) 33

[2] David H. Meikrantz, Terry A. Todd, Catherine L. Riddle, Jack D. Law, Dean R. Peterman, Bruce J. Mincher, Christopher A. McGrath, John D. Baker, US Patent 7291316 (2007), "Cesium and strontium extraction using a mixed extractant solvent including crown ether and calixarene extractants".

[3] Dmitry M. Rudkevich, US Patent 7282083 (2007), "Methods, systems, and uses for calixarenes".

[4] Koji Kishi, Tsutomu Kakuyama, Koji Ochiai, US Patent 6986998 (2006), "Method of analyzing components in biological samples".

[5] Antonius Helena Adolf Bom, Alan William Muir, David Rees, US Patent 7265099 (2007) "Use of chemical chelators as reversal agents for drug-induced neuromuscular block".

[6] Wolf Hans-Uwe; Dormann Jorg M., EP1551458 (2006) "Calixarenes for use as excipient for an active substance".

[7] Gerhard Anthony Symons, David Robert Hampton, GB 2448153 (2008) "Coated Implantable Medical Devices".

\section{BibliografiA ADICIONAL}

- V. Böhmer, Angew. Chem. Int. Ed. Engl. 34 (1995) 713.

- J. Vicens, V. Böhmer, (editors), Calixarenes: a Versatile Class of Macrocyclic Compounds, Kluwer Academis Publishers, Dordrecht, 1991

- C. D. Gutsche, Calixarenes Revisited, RSC Pub., Manchester, 1998.

- S. Félix, Síntese, Estudos Conformacionais e Aplicação de Dihomooxacalix[4]arenos, (Tese de Doutoramento), Universidade de Lisboa, 2000.

- G. J. Lumetta, R. D. Rogers, A. S. Gopalan (editors), Calixarenes for Separations, ACS, Washington, DC, 2000.

- L. Mandolini, R. Ungaro (editors), Calixarenes in Action, Imperial College Press, London, 2000.

- Z. Asfari, V. Böhmer, J. Harrowfield, J. Vicens(editors), Calixarenes 2001, Kluwer Academis Publishers, Dordrecht, 2001.

- J. Vicens, J. Harrowfield (editors), Calixarenes in the Nanoworld, Springer, Dordrecht, 2007.

- Portal Patent Storm (http://www.patentstorm.us, acedido em Janeiro de 2009).

- Portal Espacenet (http://www.espacenet. com, acedido em Janeiro de 2009). 


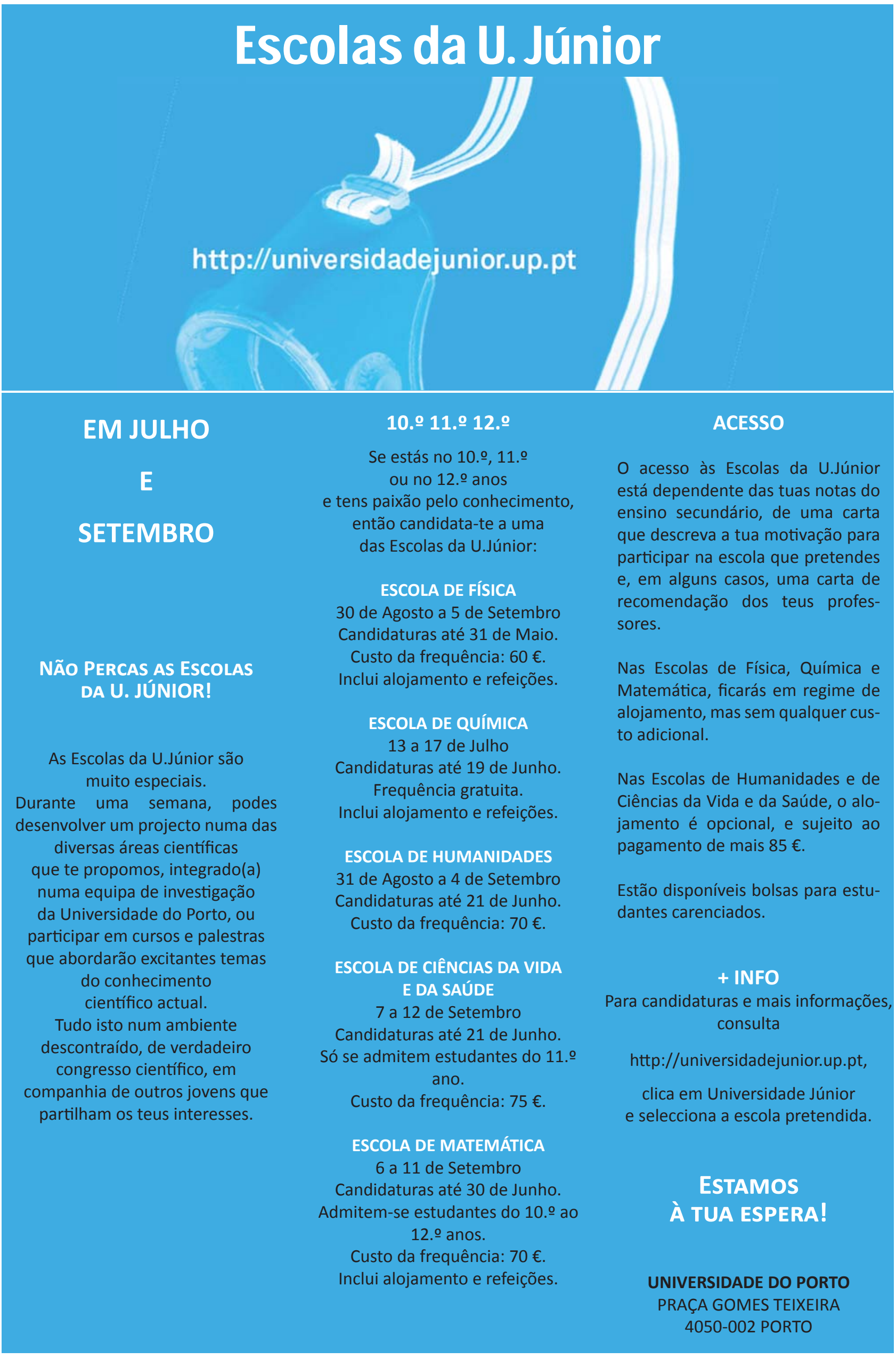




\section{Actualidade Científica}

\section{AprisionAndo o fogo}

O fósforo branco, P4, é extraordinariamente reactivo, reagindo espontaneamente com o oxigénio molecular. Esta combustão espontânea, por exposição ar, está na origem da sua utilização em fogo de artifício e em armamento, estando o seu uso bélico (cujo início remonta à Primeira Guerra Mundial) banido pelas Convenções de Genebra.

$$
\mathrm{P}_{4}(\mathrm{~s})+5 \mathrm{O}_{2}(\mathrm{~g}) \rightarrow \mathrm{P}_{4} \mathrm{O}_{10}(\mathrm{~s})
$$

O fósforo branco deve ser guardado em água para não se inflamar espontaneamente. Contudo $\mathrm{P}_{4}$ é hidrofóbico, não se dissolvendo na água.

Se $\mathrm{P}_{4}$ for colocado em contacto com uma quantidade limitada de oxigénio observa-se uma combustão quimiluminescente. Os primeiros químicos designaram este processo de emissão de luz por "fosforescência", tendo o significado deste termo entretanto mudado.

Um grupo de químicos da Universidade de Cambridge, no Reino Unido, liderado por Jonathan Nitschke, em colaboração com um investigador da Universidade de Jyväskylä, na Finlândia, construiu uma gaiola molecular que aprisiona $0 \mathrm{P}_{4}$ e que impede a sua combustão, quando na presença de oxigénio molecular. A estabilidade do fósforo no interior da gaiola resulta não da exclusão do oxigénio mas do constrangimento das moléculas de $\mathrm{P}_{4}$, de modo que não há espaço no seu interior para a formação dos produtos da reacção de combustão. O fósforo pode ser deslocado do interior da gaiola quando na presença de benzeno, que é um hóspede competitivo com $\mathrm{P}_{4}$.

Este trabalho encontra-se descrito no número de 26 de Junho da revista Science.

A gaiola forma-se por auto-organização (self-assembly) em água, usando iões $\mathrm{Fe}^{2+}$ e ligandos, segundo o esquema que se reproduz abaixo:
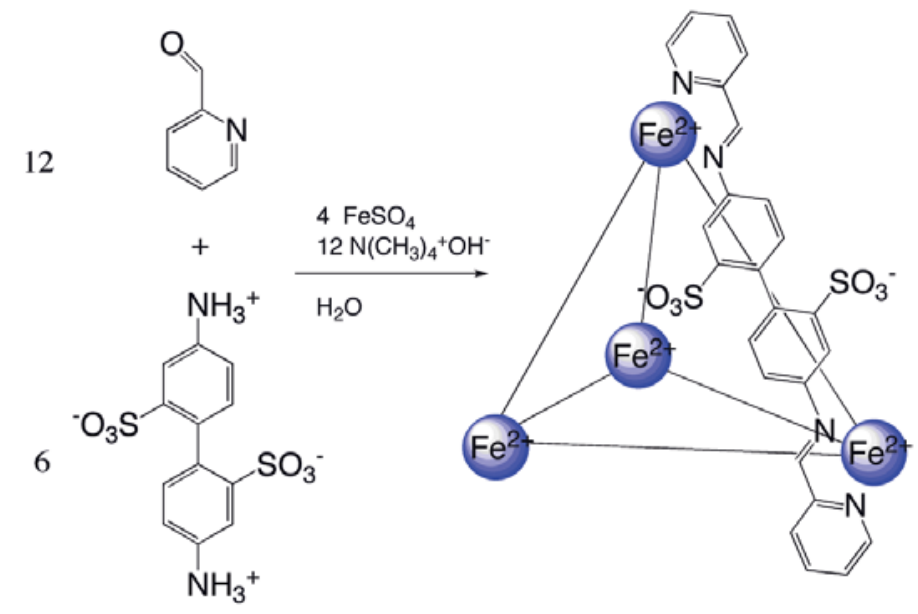

Gaiola 1

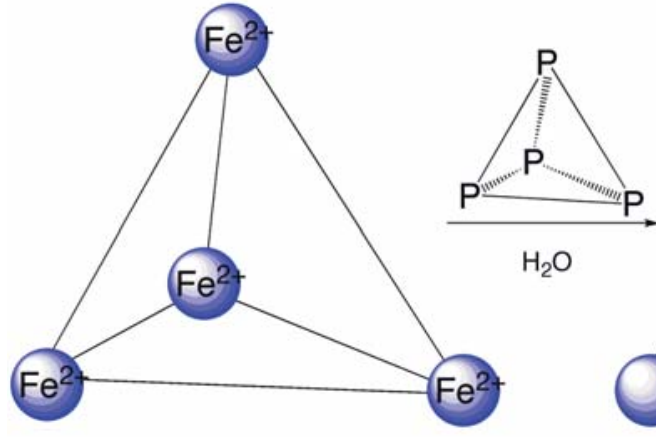

Gaiola 1

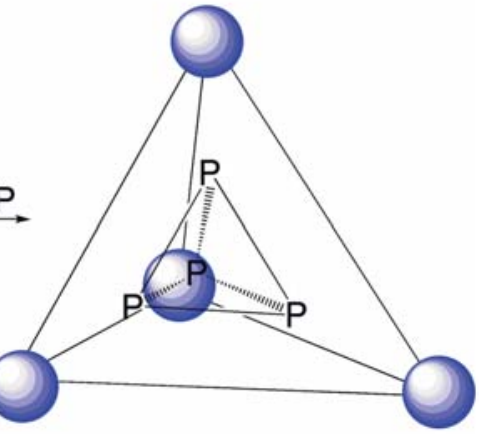

$\mathrm{P}_{4} \subset 1$
Colocando $\mathrm{P}_{4}$ sólido em contacto com estas gaiolas em água, há uma incorporação do $\mathrm{P}_{4}$ hidrofóbico no interior destas gaiolas.

A estrutura cristalina do conjunto, $\mathrm{P}_{4} \subset 1$, revela a presença de poros nas faces do tetraedro-gaiola com um raio de $1,0 \AA$, que embora sendo inferior ao raio da secção da molécula de $\mathrm{O}_{2}(1,4 \AA)$, não impediria o $\mathrm{O}_{2}$ de entrar, considerando flutuações térmicas.

Aliás são estas flutuações que permitem a entrada das moléculas de $P_{4}$. A estabilidade na presença de $\mathrm{O}_{2}$ não é pois atribuída à exclusão do $\mathrm{O}_{2}$ do interior da gaiola.

$\mathrm{O} \mathrm{P}_{4}$ encapsulado parece ser indefinidamente estável. Se uma solução aquosa de $\mathrm{P}_{4} \subset 1$ for colocada em contacto com uma solução imiscível de benzeno em hexano, há uma deslocação do $\mathrm{P}_{4}$ do interior da gaiola, que passa a ser ocupada pelo benzeno.

A exposição ao ar da solução de hexano contendo $\circ \mathrm{P}_{4}$ extraído leva à reacção e consumo do $\mathrm{P}_{4}$. 